\title{
Redundancy Design of Modular DC Solid-State Transformer Based on Reliability and Efficiency Evaluation
}

\author{
Yang LI, Yan ZHANG, Rui CAO, Xue LIU, Chunlin LV, and Jinjun LIU
}

\begin{abstract}
The modular DC solid-state transformer (DC-SST) is promising but restricted by limited reliability, which can be solved by redundancy. However, current redundancy designs are only based on the reliability evaluation in stable operation condition and seldom efficiency. In this paper, a redundancy design method of DC-SST is proposed considering both reliability and efficiency. The long-term mission profile and aging of power semiconductor devices (PSDs) and capacitors are considered in the reliability evaluation. Based on the result that the capacitor reliability dominates the system reliability, a simplified system reliability model is proposed. Besides, IGBT power loss considering the long-term mission profile is obtained, which dominates the system power loss. Finally, a multi-objective optimization is solved to obtain the optimal redundant number. Feasibility of the proposed method is verified by a prototype.
\end{abstract}

Index Terms-DC solid-state transformer, multi-objective optimization, power loss model, redundancy design, reliability evaluation.

\section{INTRODUCTION}

$\mathrm{W}$ ITH the development of smart grid, active distribution network, energy Internet and other emerging technologies, solid-state Transformer (SST), which combines the functions of electrical isolation, voltage transformation and reactive compensation, has become a key equipment to improve the integration and intelligence level of grid system. Compared with traditional line-frequency transformers, SST have significant advantages of high efficiency, low costs, and high controllability. However, the reliability of SST is widely concerned due to the use of a large number of power devices, which has become one of the key technical bottlenecks restricting its application.

Generally, the widely used solid-state transformer has a five-stage structure, among which the DC-DC converter that

Manuscript received February 28, 2021; revised April 30, 2021; accepted May 7, 2021. Date of publication June 30, 2021; date of current version June 16, 2021. This work was supported in part by the National Key Research \& Development Plan under Grant 2018YFB0905800 and in part by the State Key Laboratory of Electrical Insulation and Power Equipment. This paper was presented in part at the 4th International Conference on HVDC (HVDC 2020), Xi'an, China, September 2020. (Corresponding authors: Yan Zhang, Jinjun Liu.)

All authors are with School of Electrical Engineering, Xi'an Jiaotong University, Xi’an, Shannxi, 710000, China (e-mail: zhangyanjtu@xjtu.edu.cn; jjliu@mail.xjtu. edu.cn).

Digital Object Identifier 10.24295/CPSSTPEA.2021.00010 undertakes the high-frequency isolation function is also called the DC solid-state transformer (DC-SST) [1]. However, most reliability evaluations are based on AC converters [2]-[4], and researches about the reliability evaluation of DC-SST are relatively few. In [5], an optimized design method for DC-SST based on SiC MOSFET has been given. Besides, the lifetime of Si IGBT and SiC MOSFET have been compared under the daily load curve of the distribution network. However, the lifetime assessment for DC-SST only considers the thermal stress of the power semiconductor devices (PSDs), and does not include PSD aging and capacitor reliability. In addition, limited to the simulation speed of the simulation software, [5] did not perform the reliability assessment of DC-SST under the annual mission profile. Therefore, the system-level reliability assessment of DC-SST considering aging information of PSDs and capacitors under the long-term mission profile needs to be resolved urgently.

Since the DC-SST is the interface connecting the medium and low voltage distribution network, there is a large voltage level difference between the primary and secondary sides. To meet the voltage and current requirements of PSDs, the DCSST usually adopts a modular structure. Redundancy is one important measure to improve the reliability of the modular converter, including the DC-SST. The results of the reliability evaluation are usually used to guide the redundancy design of the system. For instance, in [6], the optimal cell number for the cascaded H-bridge (CHB) and the cascaded neutral-point clamped circuit (CNB) has been determined. Based on the optimal cascaded cell number, mean time to failures (MTTFs) under different redundant cell numbers have been analyzed. In [7], the reliability of IGBTs and capacitors in modular multilevel converters (MMC) have been evaluated separately, and the evaluation results are used to guide the redundancy design of MMC. In [8], the reliability of MMC has been evaluated considering the relevance of sub-modules, and the optimal module redundancy configuration scheme of MMC has been proposed based on the evaluation results. It is worth noting that when evaluating reliability, the above-mentioned research is only based on the stationary operation of the converter, and it is assumed that power devices have a constant failure rate. In fact, the long-term mission profile (ambient temperature, load fluctuation, wind speed, etc.) changes drastically, which will seriously affect the lifetime of power devices and converters. Moreover, the aging of critical components such as PSDs and 


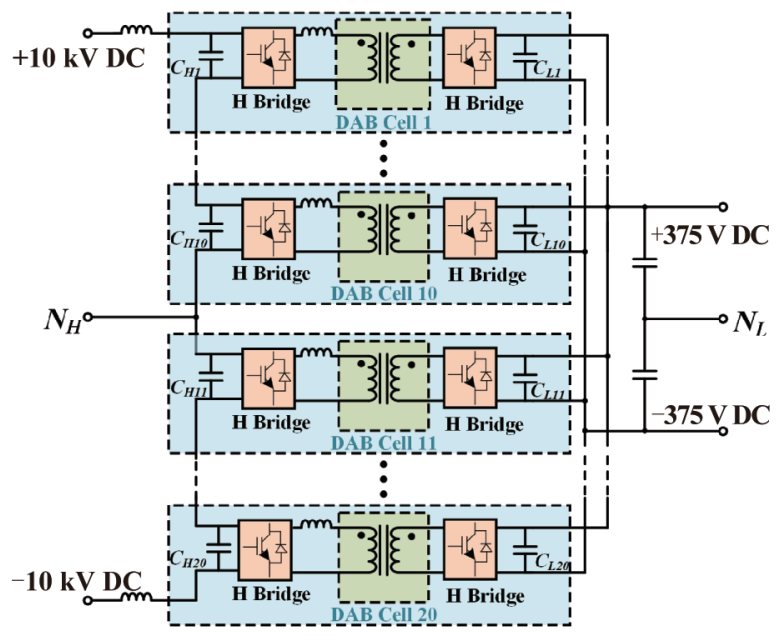

Fig. 1. The topology of a 1.5 MW DC-SST.

capacitors are not considered in reliability assessment, which has significant effects on the accuracy of reliability evaluation results [9]-[11]. Therefore, the redundancy design based on evaluation results in [6]-[8] is not accurate enough. In the reliability evaluation, both the long-term mission profile of the converter and the aging of critical components should be taken into account at the same time. Besides, the design with more cells also induces higher power loss, especially for DCSST consisting of DAB cells [12], [13], which should also be balanced with the reliability in the redundancy design.

To provide a comprehensive redundancy design method, the reliability of the modular DC-SST for power distribution is evaluated, considering the long-term mission profile and aging of critical devices. A simplified system reliability model is proposed based on the analysis of the reliability evaluation result. Finally, the optimal cell redundant number is identified by balancing efficiency and reliability.

This paper is organized as follows. The fundamentals of DCSST are illustrated in Section II. The power loss and reliability evaluation of PSDs and capacitors are conducted in Section III. Section IV presents the system reliability model and the evaluation results analysis. Based on the analysis, a simplified system reliability model is proposed and a multi-objective optimization is solved to obtain the optimal cell redundant number in Section V. The proposed method is verified by a prototype in Section VI. Finally, this paper is concluded in Section VII.

\section{FunDAMENTALS OF DC-SST}

\section{A. Topology and Specification}

The configuration of a 1.5 MW modular DC-SST for distribution network is shown in Fig. 1, which adopts the input series and output parallel (ISOP) structure. There are 20 cells in the initial design, and each cell adopts DAB topology with single phase shift modulation. Infineon's IGBT half-bridge module (FF450R17ME4) is selected for power semiconductor devices. The specific parameters are shown in Table I.
TABLE I

SPECIFICATION OF DC-SST

\begin{tabular}{lcc}
\hline \hline Parameters & Symbol & Value \\
\hline System rated transmission power & $P_{\text {t_rated }}$ & $1.5 \mathrm{MW}$ \\
System rated DC-link voltage & $V_{\text {in_ rated }}$ & $20 \mathrm{kV}$ \\
System rated output voltage & $V_{\mathrm{o}_{\mathrm{o}} \text { rated }}$ & $750 \mathrm{~V}$ \\
Number of initial cells & $N_{0}$ & 20 \\
Switching frequency & $f_{\mathrm{s}}$ & $20 \mathrm{kHz}$ \\
Transformer ratio of transformers & $k$ & $4: 3$ \\
Inductor & $L$ & $55.2 \mu \mathrm{H}$ \\
Input capacitor & $C_{\mathrm{i}}$ & $1000 \mu \mathrm{F}$ \\
Output capacitor & $C_{\mathrm{o}}$ & $1000 \mu \mathrm{F}$ \\
\hline \hline
\end{tabular}

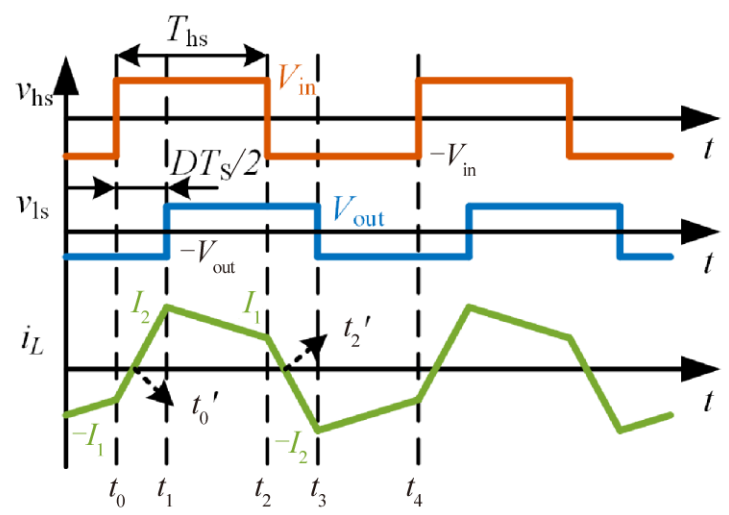

Fig. 2. The inductor current in DAB cell under single phase-shift modulation.

\section{B. Operation Principle}

Fig. 2 shows the waveform of voltage and current in DAB cells. The phase difference between voltages of primary and secondary sides is controlled to charge the inductor, and then the power transmission between input and output sides is accomplished. The phase shift duty ratio $D$ is (1).

$$
D=\frac{2 t_{\mathrm{d}}}{T_{\mathrm{s}}}=0.5 \cdot\left(1-\sqrt{1-\frac{8 P_{\mathrm{L} \_ \text {tot }} f_{\mathrm{s}} L}{k V_{\text {in_tot }} V_{\text {o_tot }}}}\right)
$$

On the effect of H-bridges, voltages across both primary and secondary sides of high frequency transformer are square wave $v_{\mathrm{hs}}$ and $v_{\mathrm{ls}}$, whose direction determines whether the upper or lower arm conducts in a half-bridge. Meanwhile, the direction of the inductor current $i_{L}$ determines whether the IGBT or the diode conducts on the conducting arm. According to the former analysis, the switching-off current of primary side IGBT is $I_{1}$, whereas the one of secondary side IGBT is $I_{2}$, which can be represented as (2) and (3), where $N$ is DAB cell number in the DC-SST, and $k$ is high frequency transformer ratio.

$$
\begin{aligned}
& I_{1}=\frac{V_{\text {in_tot }}-N k V_{\text {o_tot }} \sqrt{1-\frac{8 P_{\mathrm{t} \text { tot }} f_{\mathrm{s}} L}{k V_{\text {in tot }} V_{\text {o tot }}}}}{4 N f_{\mathrm{s}} L} \\
& I_{2}=\frac{N k V_{\text {o_tot }}-V_{\text {in_tot }} \sqrt{1-\frac{8 P_{\text {t tot }} f_{\mathrm{s}} L}{k V_{\text {in_tot }} V_{\text {o tot }}}}}{4 N f_{\mathrm{s}} L}
\end{aligned}
$$




\section{Power Loss and Reliability of Components}

PSDs and capacitors are two most fragile components in the power electronic equipment [14]. This section presents the PSD and capacitor reliability estimation process including aging information. The power loss model including $N$ and thermal model of components are given, which are also necessary for power loss calculation. Based on these models, the annual power loss and temperature variation is obtained. Their lifetimes are obtained by lifetime models. The compnent reliability can be obtained through the Monte Carlo method and curve fitting.

\section{A. PSD Power Loss}

IGBT power loss mainly includes conduction loss and switching loss. The turn-on loss of the power diode is small enough, and generally only its reverse recovery loss and conduction loss are considered.

\section{1) Conduction Loss}

The conduction loss of IGBT and diode in a switching cycle can be calculated by (4) and (5).

$$
\begin{gathered}
p_{\text {cond }}^{\text {IGBT }}\left(N, T_{\mathrm{j}}\right)=\int_{0}^{1 / f_{\mathrm{s}}} v_{\text {ce }}^{\text {IGBT }}\left(i_{\text {ce }}^{\text {IGBT }}(N), T_{\mathrm{j}}\right) \cdot i_{\text {ce }}^{\text {IGBT }}(N) \cdot \mathrm{d} t \\
p_{\text {cond }}^{\text {Diode }}\left(N, T_{\mathrm{j}}\right)=\int_{0}^{1 / f_{\mathrm{s}}} v_{\mathrm{T}}^{\text {Diode }}\left(i_{\mathrm{d}}^{\text {Diode }}(N), T_{\mathrm{j}}\right) \cdot i_{\mathrm{d}}^{\text {Diode }}(N) \cdot \mathrm{d} t
\end{gathered}
$$

The conduction loss is determined by the current flowing through IGBT and diode $\left(i_{\mathrm{ce}}^{\mathrm{IGBT}}, i_{\mathrm{d}}^{\text {Diode }}\right)$ and the forward voltage $\left(v_{\mathrm{ce}}^{\mathrm{IGBT}}, v_{\mathrm{T}}^{\text {Diode }}\right)$. The forward voltage is related to the current flowing through PSDs and junction temperature $\left(T_{\mathrm{j}}\right)$. The corresponding relationship can be obtained by fitting the curve provided by the device manual, as shown in (6) and (7).

$$
\begin{aligned}
V_{\text {ce }}\left(i_{\text {ce }}^{\text {IGBT }}(N), T_{\mathrm{j}}\right)= & \left(a_{0} \cdot T_{\mathrm{j}}+a_{1}\right) \cdot\left(i_{\text {ce }}^{\text {IGBT }}\right)^{2} \\
& +\left(a_{2} \cdot T_{\mathrm{j}}+a_{3}\right) \cdot i_{\text {ce }}^{\text {IGBT }}+a_{4} \cdot T_{\mathrm{j}}+a_{5} \\
V_{\mathrm{T}}\left(i_{\mathrm{d}}^{\text {Diode }}(N), T_{\mathrm{j}}\right)= & \left(b_{0} \cdot T_{\mathrm{j}}+b_{1}\right) \cdot\left(i_{\mathrm{d}}^{\text {Diode }}\right)^{2} \\
& +\left(b_{2} \cdot T_{\mathrm{j}}+b_{3}\right) \cdot i_{\mathrm{d}}^{\text {Diode }}+b_{4} \cdot T_{\mathrm{j}}+b_{5}
\end{aligned}
$$

\section{2) Switching Loss}

Generally, the relationship curve between switching energy ( $\left.E_{\text {on }}, E_{\text {off }}, E_{\text {rec }}\right)$, junction temperature $\left(T_{\mathrm{j}}\right)$ and switching current $\left(I_{1}, I_{2}, I_{1}^{\prime}, I_{2}^{\prime}\right)$ is given in the device manual, and the switching loss model is established as (8) and (9).

$$
\begin{aligned}
& p_{\text {sw_off }}^{\text {IGBT_pri }}\left(N, T_{\mathrm{j}}\right)=f_{\text {sw }} \cdot E_{\text {off }}\left(I_{1}(N), T_{\mathrm{j}}\right) \cdot \frac{V_{\text {in }}(N)}{V_{\text {ref }}} \\
& p_{\text {sw_off }}^{\text {IGBT_sec }}\left(N, T_{\mathrm{j}}\right)=f_{\text {sw }} \cdot E_{\text {off }}\left(I^{\prime}{ }_{2}(N), T_{\mathrm{j}}\right) \cdot \frac{V_{\text {out }}(N)}{V_{\text {ref }}}
\end{aligned}
$$

Obviously, the switching loss is related to switching energy, junction temperature $\left(T_{\mathrm{j}}\right)$, switching frequency $\left(f_{\mathrm{sw}}\right)$, and

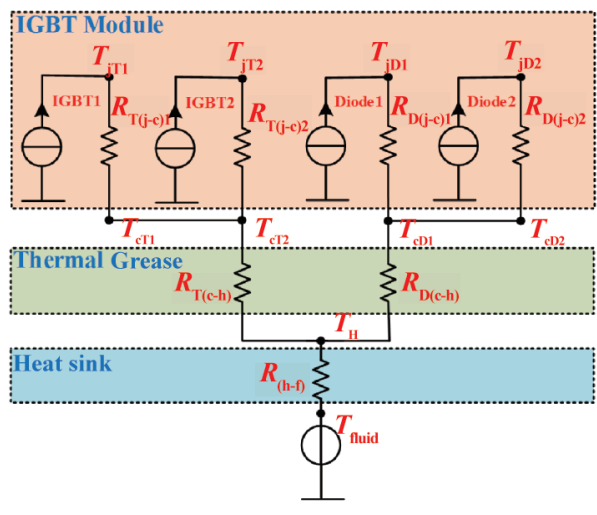

Fig. 3. Thermal network of IGBT module.

blocking voltage $\left(V_{\text {in }}, V_{\text {out }}\right)$. The switching energy is related to the switching current and junction temperature of PSDs. The corresponding relationship can be obtained by fitting the curve provided by the device manual, as shown in (10).

$$
E_{\text {off }}\left(i, T_{\mathrm{j}}\right)=\left(d_{0} \cdot i^{3}+d_{1} \cdot i^{2}+d_{2} \cdot i\right) \cdot\left(d_{3} \cdot T_{\mathrm{j}}+d_{4}\right)
$$

\section{3) Electric and Heating Interaction}

According to the former power loss model, $T_{\mathrm{j}}$ also influences power loss. Therefore, the thermal model has to be constructed. The thermal characteristics of the PSDs is usually modeled by the Foster model, which consists of a series of thermal resistors and capacitors [15]. However, since load fluctuation period in the distribution network is much larger than the thermal time constant of PSDs, the effect of $T_{\mathrm{j}}$ transient can be ignored. Therefore, only thermal resistance $\left(R_{\mathrm{th}}\right)$ is considered for longterm thermal load analysis, and the long-term $T_{\mathrm{j}}$ is composed of the steady-state $T_{\mathrm{j}}$ under different loads. Thermal network of PSDs is shown in Fig. 3. The steady-state junction and case temperature $\left(T_{\mathrm{j}}\right.$ and $\left.T_{\mathrm{c}}\right)$ can be obtained by $(11) . T_{\mathrm{jT} / \mathrm{D}}$ represents $T_{\mathrm{j}}$ of the IGBT or diode, and $T_{\mathrm{cT} / \mathrm{cD}}$ represents $T_{\mathrm{c}}$ of the IGBT or diode. $R_{\mathrm{T} / \mathrm{D}(\mathrm{j}-\mathrm{c})}$ represents the thermal resistance of IGBT and diode from junction to case, and $R_{\mathrm{T} / \mathrm{D}(\mathrm{c}-\mathrm{h})}$ represents the thermal resistance of IGBT and diode from case to the heatsink. The liquid temperature $\left(T_{\text {fluid }}\right)$ of the water-cooled heatsink maintains $25^{\circ} \mathrm{C}$, and the thermal resistance of the heatsink $\left(R_{\mathrm{h}-\mathrm{f}}\right)$ is $10 \mathrm{~K} / \mathrm{kW}$ [16].

$$
\left\{\begin{array}{l}
T_{\mathrm{jT} / \mathrm{jD}}=P_{\text {loss } \mathrm{T} / \mathrm{D}} \cdot\left(R_{\mathrm{T} / \mathrm{D}(\mathrm{j}-\mathrm{c})}+R_{\mathrm{T} / \mathrm{D}(\mathrm{c}-\mathrm{h})}+R_{\mathrm{h}-\mathrm{f}}\right)+T_{\text {fluid }} \\
T_{\mathrm{c} \mathrm{T} / \mathrm{c} \mathrm{D}}=P_{\text {loss } \mathrm{T} / \mathrm{D}} \cdot\left(R_{\mathrm{T} / \mathrm{D}(\mathrm{c}-\mathrm{h})}+R_{\mathrm{h}-\mathrm{f}}\right)+T_{\text {fluid }}
\end{array}\right.
$$

The former modeling also illustrates the electric and heating interaction between power loss and temperature. Iteration is used for precise power loss and thermal profile calculation.

\section{B. PSD Lifetime Evaluation Based on Thermal Profile}

Based on the proposed electric and heating interaction model, the thermal load of PSDs under the annual load profile can be obtained by substituting the mission profile and the cell number $(N)$. Fig. 4 shows the annual $T_{\mathrm{j}}$ and $T_{\mathrm{c}}$ of IGBT 


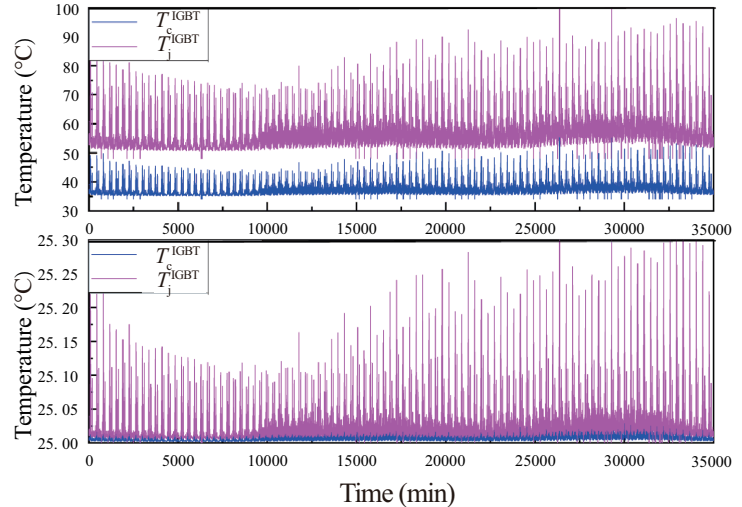

Fig. 4. Annual curves of junction temperature and case temperature of IGBT and diode on the primary side of a DAB cell.

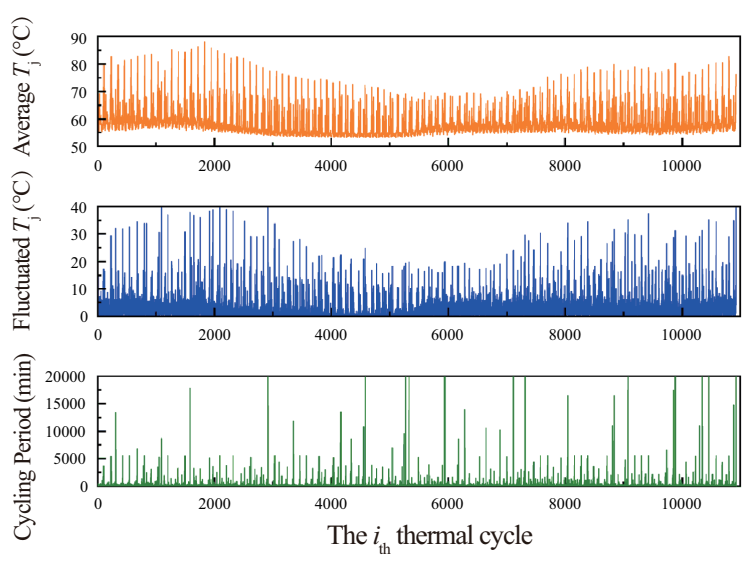

Fig. 5. Results of the rainflow algorithm for the annual junction temperature curve of the IGBT in Fig. 4.

and diode on the primary side of the DAB cell when $N$ is 20 . Within one year, $T_{\mathrm{j}}$ and $T_{\mathrm{c}}$ fluctuated sharply and the range is relatively large. The rainflow algorithm is used to convert the thermal profile into a series of thermal cycles. As illustrated in Fig. 5, 10918 thermal cycles of the annual $T_{\mathrm{j}}^{\mathrm{IGBT}}$ are counted, and the $T_{\mathrm{j}}$ fluctuation amplitude $\left(\Delta T_{\mathrm{j}}\right)$, the average $T_{\mathrm{j}}\left(T_{\mathrm{jm}}\right)$ and the cycle period $\left(t_{\mathrm{sw}}\right)$ under each cycle are extracted.

Manufacturers have given many empirical lifetime models of IGBTs based on accelerated aging tests. The NorrisLandzerg Model [17] is selected to calculate the number of cycles to failure $\left(N_{\mathrm{f}}\right)$ under the $i_{\text {th }}$ counting cycle in Fig. 4 . This model is relatively simple and takes into account the impact of the cycle period, as shown in (12). The coefficients $A, \alpha, \beta$, and $\gamma$ are obtained by fitting the data provided from accelerated aging tests [18]. As shown in Table II, the accelerated aging data consists of data at three positions of the IGBT module, including the bond wire (BW), the chip solder (CS), and the base plate solder (BS) of IGBTs and diodes. Therefore, three lifetime models are used to obtain $N_{\mathrm{f}}$ at corresponding positions of the IGBT and the diode respectively.

$$
N_{\mathrm{f}}^{\mathrm{CS} / \mathrm{BW} / \mathrm{BS}}\left(\Delta T, T_{\mathrm{jm}}, t_{\mathrm{sw}}\right)=A \cdot\left(\frac{1}{t_{\mathrm{sw}}}\right)^{\alpha} \cdot \Delta T^{-\beta} \cdot e^{\frac{\gamma}{T_{\mathrm{jm}}}}
$$

TABLE II

Parameters of Lifetime Model

\begin{tabular}{lccc}
\hline \hline Position & CS & BW & BS \\
\hline$A$ & $6.0235 \times 10^{8}$ & $3.6238 \times 10^{10}$ & $1.9651 \times 10^{9}$ \\
$\alpha$ & -0.5852 & 0 & -0.1718 \\
$\beta$ & 4.8746 & 4.2368 & 3.8249 \\
$\gamma$ & 5751.3 & 2449 & 2438.3 \\
\hline \hline
\end{tabular}

After calculating $N_{\mathrm{f}}$, according to Miner's rule [19], the cumulative damage to CS, BW, and BS of PSDs under different thermal cycles in the annual mission profile is calculated by (13). $C L_{\text {IGBT/Diode }}^{\mathrm{CS} B \mathrm{BW} / \mathrm{s}}$ represents the cumulative damage of different positions of PSDs. $N_{\mathrm{f}, \mathrm{i}}^{\mathrm{CS} / \mathrm{BW} / \mathrm{BS}}$ represents $N_{\mathrm{f}}$ corresponding to different positions of PSDs under the ith thermal cycle.

$$
C L_{\mathrm{IGBT} / \mathrm{Diode}}^{\mathrm{CS} / \mathrm{B} / \mathrm{BS}}=\sum_{i=1}^{n} \frac{1}{N_{\mathrm{f}, \mathrm{i}}^{\mathrm{CS} / \mathrm{BW} / \mathrm{BS}}\left(\Delta T, T_{\mathrm{jm}}, t_{\mathrm{sw}}\right)}
$$

For the IGBT and the diode, failure at any position leads to the failure of the entire component and further lead to the failure of the half-bridge module. Therefore, the IGBT module is regarded as a system and its reliability is characterized through the reliability block diagram (RBD) model. The IGBT and diode damage can be calculated by (14), and the annual cumulative damage of a half-bridge module can be calculated by (15).

According to Miner's rule [19], the predicted lifetime ( $L T)$ of the IGBT module can be calculated by (16). Similarly, the IGBT module lifetime on the secondary side is obtained.

$$
\begin{gathered}
C L_{\mathrm{IGBT} / \mathrm{Diode}}=C L_{\mathrm{IGBT} / \mathrm{Diode}}^{\mathrm{CS}}+C L_{\mathrm{IGBT} / \text { Diode }}^{\mathrm{BW}}+C L_{\mathrm{IGBT} / \text { Diode }}^{\mathrm{BS}} \\
C L_{\text {module_lyear }}=2 \cdot\left(C L_{\mathrm{IGBT}}+C L_{\text {Diode }}\right) \\
L T=1 / C L_{\text {module_lyear }}
\end{gathered}
$$

Generally, the aging of PSDs is mainly reflected in the gradual increase of $R_{\mathrm{th}}$, which intensifies thermal stress and accelerates the failure. Therefore, an accurate PSD reliability assessment should take into account the effects of aging. In this paper, the increase in $R_{\mathrm{th}}$ caused by aging of PSDs is fed back to the thermal model in sections to update the thermal load of PSDs. When the cumulative damage increases by $20 \%, R_{\text {th }}$ increases to $10 \%$ of the original [4].

\section{Capacitor Power Loss}

The power loss of capacitors is the main factor leading to its internal heating, and then accumulative failure. The power loss model of a capacitor is shown in (17).

$$
P_{\text {loss }}=\sum_{h=1}^{N} I(N)^{2} \cdot E S R
$$

$I(N)$ is the rms value of the capacitor current with $N$ cells. According to $\mathrm{DAB}$ operation principle, the rms value of input 
and output capacitor currents are calculated by (18) and (19), where $I_{\mathrm{L}_{-} \mathrm{m} s}^{\mathrm{P}}$ is the rms value of $i_{L}$.

$$
\begin{gathered}
I_{\mathrm{C}_{\_} \mathrm{ms}}^{\mathrm{P}}=\sqrt{I_{\mathrm{L}_{-} \mathrm{rms}}^{{ }^{2}-I_{\mathrm{in}}^{2}}} \\
\mathrm{I}_{\mathrm{C} \_\mathrm{rms}}=\sqrt{k^{2} I_{\mathrm{L} \_ \text {rms }}^{\mathrm{P}}-I_{\mathrm{o}}^{2}}
\end{gathered}
$$

\section{Capacitor Lifetime Evaluation Based on Thermal Profile}

Many previous researches have concluded that capacitor lifetime is seldom effected by temperature fluctuation, which is different from PSD lifetime. Therefore, the obtained thermal load profile can be utilized directly.

An improved reliability evaluation method of capacitors which takes into account the influence of harmonics on the capacitor lifetime is used in this paper [20], as shown in (20). $L_{\mathrm{i}}$ and $L_{\mathrm{N}}$ are the capacitor lifetime under the practical operating condition and rated condition, respectively. $U$ and $U_{\mathrm{N}}$ are the voltage at the practical operating condition and rated condition, respectively. $T_{\text {hs }}$ and $T_{\mathrm{N}}$ are the temperature at the hot spot and rated condition, respectively. $n$ and $\alpha$ are the voltage coefficient and temperature coefficient, which can be measured by accelerated lifetime test and selected as $n=4.4, \alpha$ $=10$ [21]. $K_{\mathrm{rms}}, K_{\mathrm{p}}$, and $K_{\mathrm{f}}$ are the root mean square coefficient, peak coefficient and waveform coefficient which are used to describe the influence of voltage harmonics. Empirical values of coefficient selection in [20] are $a=-0.5, b=-6.1$ and $c=-2.6$.

$$
\frac{L}{L_{\mathrm{N}}}=\left(\frac{U}{U_{\mathrm{N}}}\right)^{-n} 2 \frac{T_{\mathrm{N}}-T_{\mathrm{hs}}}{\alpha} K_{\mathrm{rms}}^{a} K_{\mathrm{p}}^{b} K_{\mathrm{f}}^{c}
$$

In the long-term operation, the capacitor deterioration leads to capacitance decrease and ESR increase. According to the capacitor thermal model and lifetime model, there is a coupling relationship between $T_{\text {hs }}$ and ESR: ESR increase leads to $T_{\text {hs }}$ increase, and then accelerates capacitor aging and $E S R$ growing. An improved aging model [20] deeply analyzing the capacitor aging mechanism is used to describe ESR changes and internal stress during capacitor aging process, as shown in (21). $\operatorname{ESR}(0)$ is the initial value of $E S R$, and $\beta$ is the temperature coefficient.

$$
\operatorname{ESR}(t)=\operatorname{ESR}(0) \exp \left[\left(\frac{U}{U_{\mathrm{N}}}\right)^{-n} K_{\mathrm{rms}}^{a} K_{\mathrm{p}}^{b} K_{\mathrm{f}}^{c} \int_{0}^{t} 2^{\frac{T_{\mathrm{ts}}}{\beta}} \mathrm{d} t\right]
$$

In order to accurately evaluate capacitor reliability under the long-term mission profile, varying stress needs to be considered. According to cumulative damage principle, the entire lifetime cycle of a capacitor is divided into multiple small periods, and then the lifetime model (20) is used to calculate the capacitor expected lifetime under the current operation condition. Meanwhile, the expected lifetime is converted to capacitance loss within multiple small time periods [20]. The cumulative damage model is shown in (22), where $t_{\mathrm{p}}$ is the

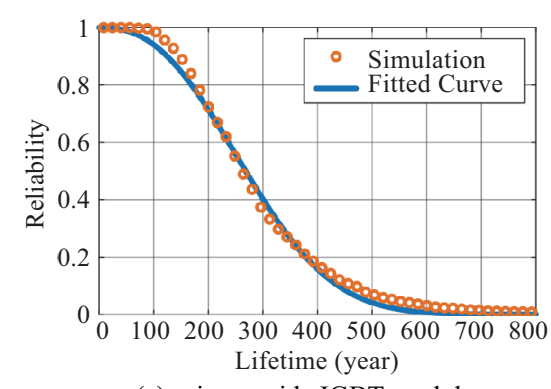

(a) primary side IGBT module

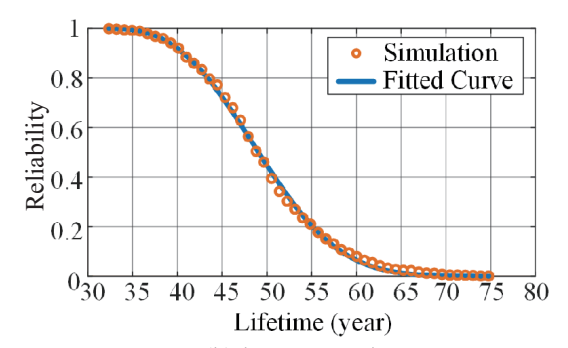

(b) input capacitor

Fig. 6. The component reliability fitting results $(N=20)$.

given period.

$$
\triangle C(n)=\sum_{i=1}^{n} \frac{t_{\mathrm{p}}}{L_{i}(t)} \cdot 5 \% C
$$

\section{E. Monte Carlo Method and Component Reliability}

The proposed lifetime models can only obtain a predicted lifetime of a specific device. However, the inevitable individual differences caused by the processing process lead to certain differences in lifetime model parameters and basic parameters of different devices. Assuming that lifetime model parameters and thermal resistance obey the normal distribution, with a maximum 5\% deviation [22], Monte Carlo simulation is used, and each distribution is randomly sampled 1000 times to obtain 1000 sets of parameter combinations. Each combination is substituted into the corresponding component lifetime model, and lifetime distributions of IGBT modules and capacitors are fitted. As shown in Fig. 6, IGBT module reliability conforms to the Weibull distribution [23], and capacitor reliability conforms to the exponential distribution. Fig. 7 illustrates the complete reliability evaluation process for IGBT modules and capacitors.

\section{System Reliability Evaluation}

This section focuses on DC-SST system reliability evaluation. According to the reliability evaluation results of PSDs and capacitors, the RBD model is utilized to obtain the reliability of each DAB cell and DC-SST system. Results in [24] are analyzed combined with basic principles.

\section{A. System Reliability Evaluation Method}

According to the former analysis, the reliability of fragile 


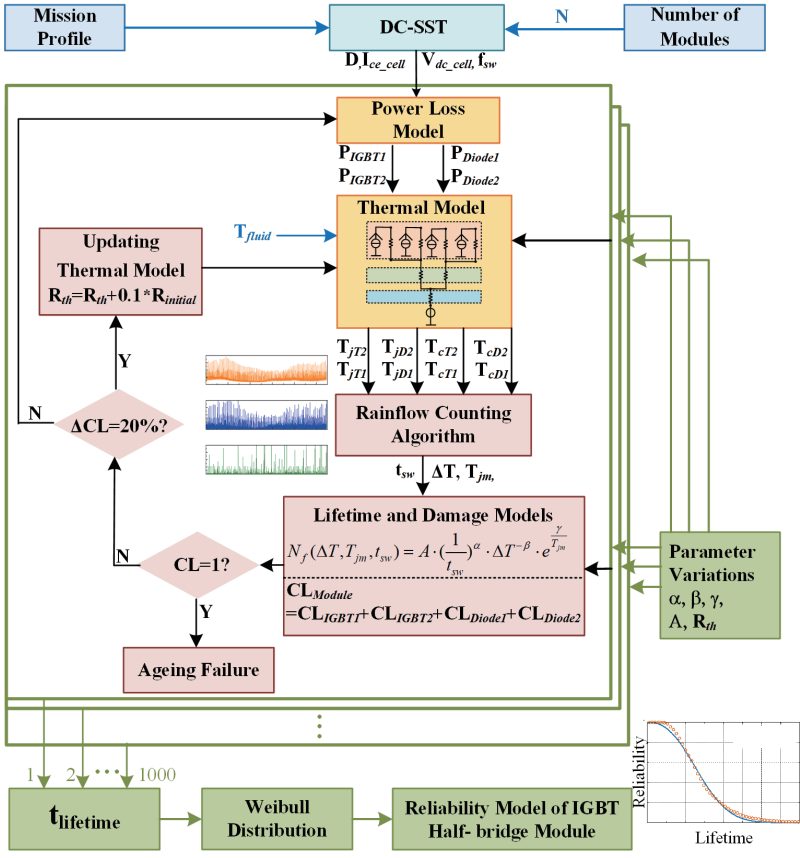

(a) IGBT modules

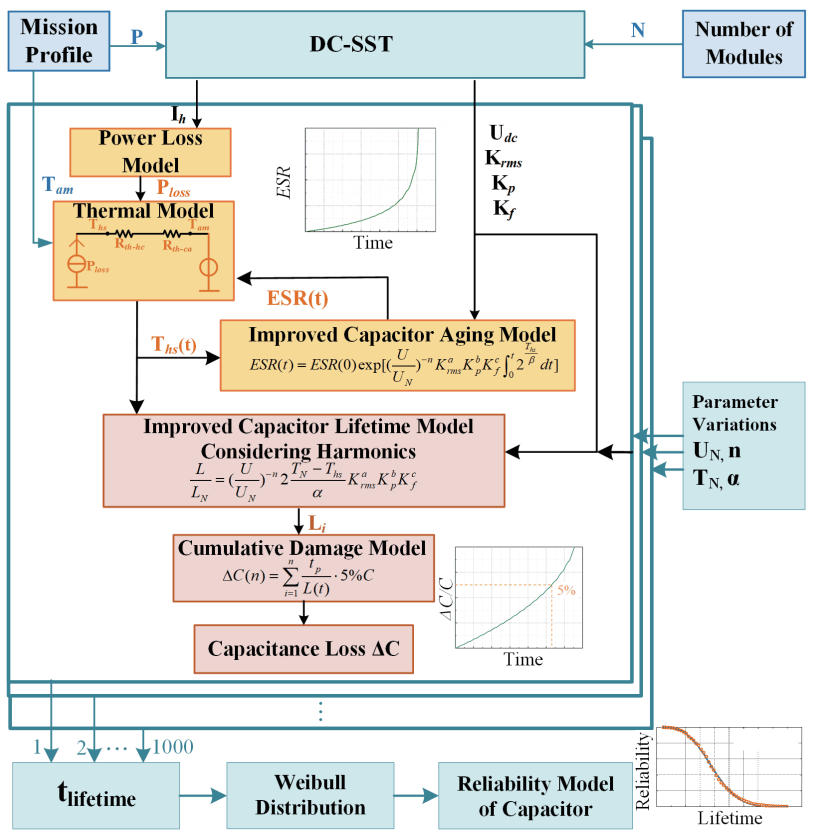

(b) Capacitors

Fig. 7. Complete coponent reliability evaluation flow charts.

devices in DAB cells is evaluated. To evaluate DC-SST system reliability and find the best redundancy design considering reliability, the reliability of DAB cells should be evaluated. The RBD model believes that the system can operate normally only when each component in the system is normal. According to the RBD model, the reliability of a DAB cell $R_{\mathrm{DAB}}(N, t)$ associated with $N$ is calculated by (23). Therefore, the reliability curves with different DAB cell numbers are shown in Fig. 8(a). It is indicated that as $N$ grows, the reliability of each DAB cell reduces, which

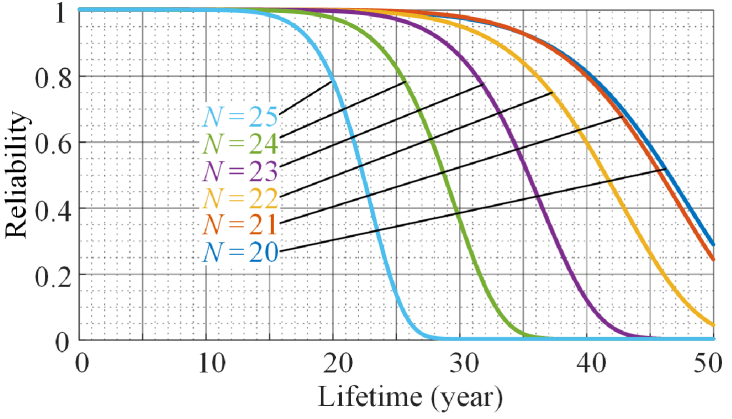

(a) DAB cell

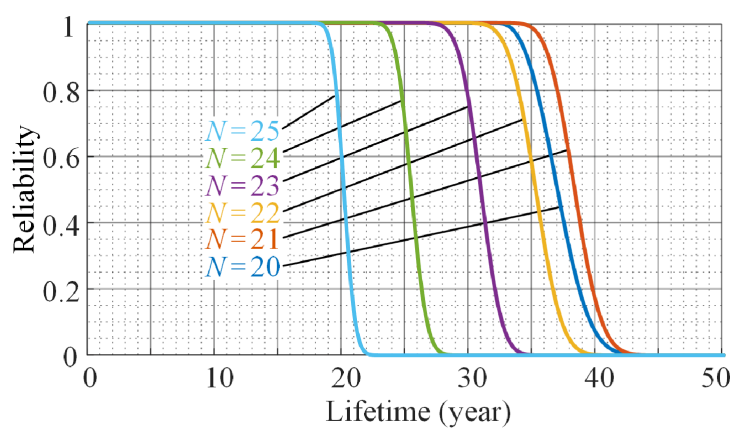

(b) DC-SST

Fig. 8. The reliability of DAB cell and DC-SST under different cell number.

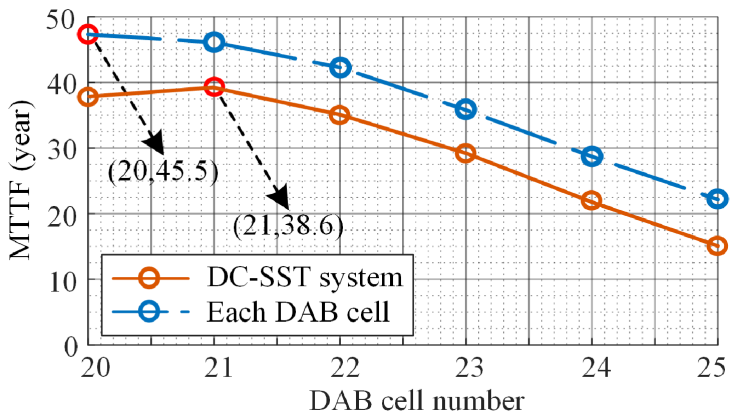

Fig. 9. MTTFs of DAB cell and DC-SST under different cell number.

causes the MTTF decrease, as shown in Fig. 9.

$R_{\mathrm{DAB}}(N, t)=\left[R_{\mathrm{IGBT}}^{\mathrm{pri}}(N, t)\right]^{2} \cdot\left[R_{\mathrm{IGBT}}^{\mathrm{sec}}(N, t)\right]^{2} \cdot R_{\mathrm{C}}^{\mathrm{pri}}(N, t) \cdot R_{\mathrm{C}}^{\mathrm{sec}}(N, t)$

The system reliability $R_{\mathrm{DC} \text { SST }}(N, t)$ depends on both $N$ and $R_{\mathrm{DAB}}(N, t)$. The DC-SST reliability is obtained by the $k$-outof- $n$ criterion [25], which is shown as (24). Here, at least 20 cells are needed in the system for normal operation. Therefore, with the assumption that the cell reliability is not related to $N$, high redundant ratio always leads to high reliability. However, since the reliability of each DAB cell reduces as $N$ grows, the system reliability varies non-linearly as $N$ grows. Fig. 8 (b) and Fig. 9 shows the reliability and MTTF of the DC-SST system with different $\mathrm{DAB}$ cell numbers respectively. When 


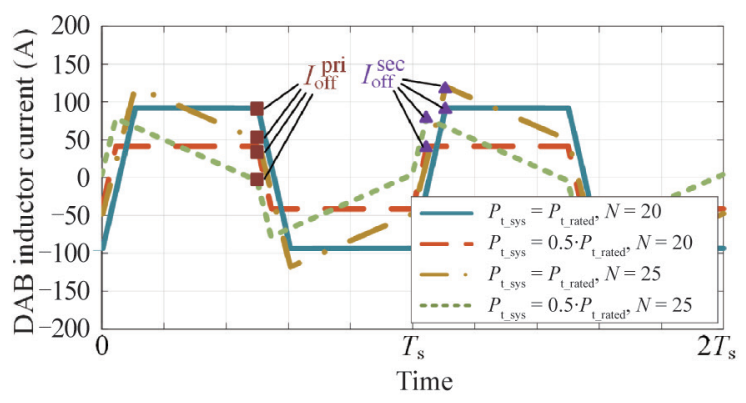

Fig. 10. DAB inductor current waveforms when DC-SST consists of different cell number and handles different $P_{\mathrm{t}-\mathrm{sy} \text {. }}$.

one redundant cell is added, the reliability of each cell slightly decreases, while the redundant ratio significantly increases. Therefore, adding one cell realizes the system reliability improvement. However, with more redundant cells, the decrease of the cell reliability dominates the system reliability, although redundancy can slightly improve it. Therefore, the system reliability decreases when more cells are added. As a consequence, as $N$ grows, both the system reliability and the MTTF increase first and then decrease. When one redundant cell is added, the system reliability reaches maximum, and the MTTF is 38.6 years.

$$
R_{\mathrm{DC} \_ \text {SST }}(N, t)=\sum_{i=20}^{N} C_{N}^{i} \cdot R_{\mathrm{DAB}}(N, t)^{i} \cdot\left[1-R_{\mathrm{DAB}}(N, t)\right]^{N-i}
$$

\section{B. Reliability Evaluation Result Analysis}

The former result shows that as $N$ grows, although the load of each cell decreases, the reliability and lifetime of each $D A B$ cell gradually reduces. It does not correspond to the empirical conclusion that a converter always has higher reliability and a longer lifetime with more cells [26]. The phenomenon is determined by the principle of DAB cells with the ISOP structure, which can be analyzed according to the inductor current shown in Fig. 10. For a certain system transmission power $P_{\mathrm{t} \text { sys }}$, when there is no redundant cell, the ratio of input to output voltages equals the transformer ratio $k$, and $i_{L}$ is trapezoidal wave. As the redundant cell number increases, the input voltage of each cell decreases, generating the inductor current distortion. The variation of inductor current impacts power loss of both IGBT modules and capacitors, and then impacts their reliability. Besides, transmission power reduction causes $i_{L}$ amplitude reduction, with the same slope of $i_{L}$ in each duration. It means the reduction of the rms value of $i_{L}$, and the reduction of IGBT turn-off current on both primary and secondary sides.

For further analysis, several characteristic currents of one DAB cell when DC-SST handles $P_{\mathrm{t} \text { rated }}$ are extracted, which are turn-off currents of IGBTs, the rms values of IGBT conduction currents and the rms values of capacitor currents. Their relationships with $N$ are shown in Fig. 11. For IGBT modules, although both $I_{\text {cond }}^{\text {IGB }}$ pri and $I_{\text {cond }}^{\mathrm{GBBT}}$ sec have less variation as $N$ increasing, $I_{\text {off }}^{\mathrm{IGBT} \text { pri }}$ significantly decreases and $I_{\text {off }}^{\mathrm{IGBT}}$ sec significantly increases due to the inductor current distortion.

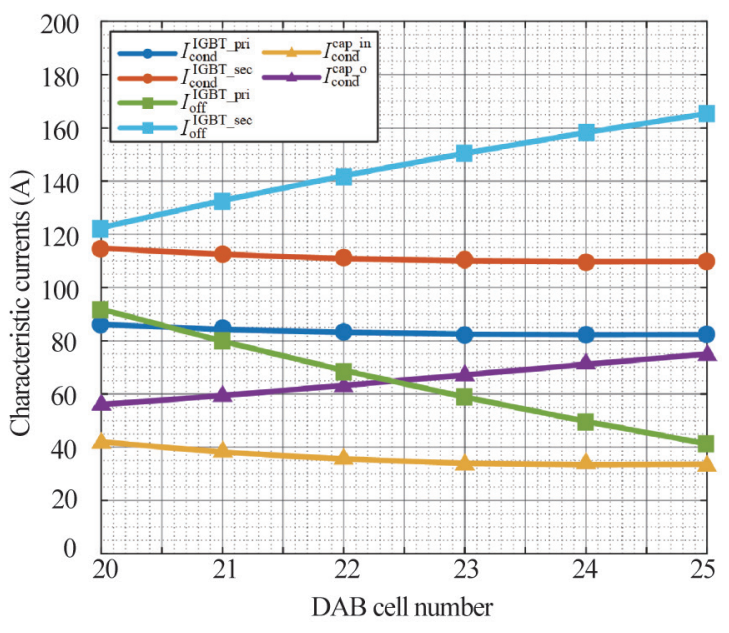

Fig. 11. Characteristic currents of one DAB cell with $P_{\mathrm{t}_{\text {rated }}}$.

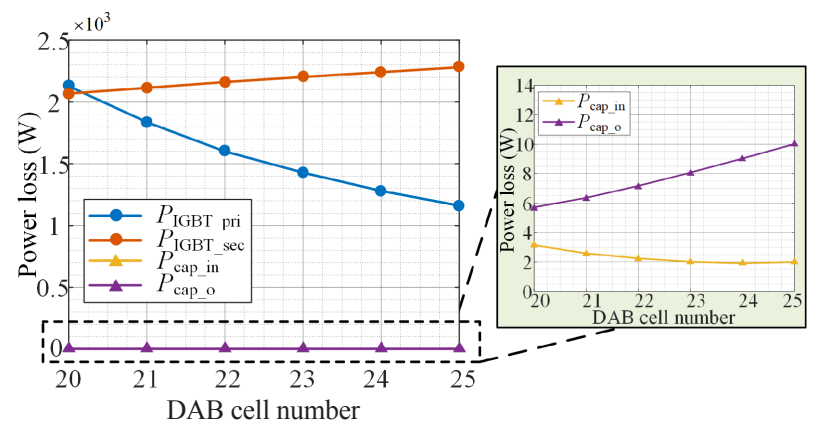

Fig. 12. Power loss of IGBT modules and capacitors with $P_{\mathrm{t} \_ \text {rated }}$ and no aging.

Since the turn-off loss predominates, the power loss of primary side IGBT modules decreases while the power loss of secondary side IGBT modules increases as $N$ increasing, as shown in Fig. 12.

As (18) and (19), for capacitors, both $I_{\text {cond }}^{\text {cap in }}$ and $I_{\text {cond }}^{\text {cap o }}$ are determined by $i_{L}$ and the input/output current. The input current has no variation as $N$ increasing, since the input voltage is always proportional to $P_{\mathrm{t} \mathrm{DAB}}$, transmission power of each $\mathrm{DAB}$ cell. Thus, $I_{\text {cond }}^{\text {cap in }}$ first slightly decreases and then slightly increases as $N$ increasing, which has the same trend as the rms value of $i_{L}$. However, due to a constant output voltage, the output current is proportional to $P_{\mathrm{t} \text { DAB }}$. Thus, $I_{\text {cond }}^{\text {cap o increases }}$ as $N$ increasing. Therefore, power loss of input capacitor first decreases and then slightly increases, while power loss of output capacitor increases as $N$ increasing, as shown in Fig. 12.

Since the reliability evaluation is based on mission profile rather than $P_{\mathrm{t} \text { rated }}$, power loss in full power range with different cell numbers is necessary. Fig. 13 illustrates power loss of IGBT modules and capacitors in full power range. For a specific $P_{\mathrm{t} \_y s}$, power loss with different cell numbers can be obtained in Fig. 14, and a figure like Fig. 12 can be plotted.

As shown in Fig. 13(c) and (d), the trends of input capacitor power loss changing with $N$ are different when $P_{\mathrm{t} \text { sys }}$ is different, whereas the trends of output capacitor power loss are similar and always monotone increasing. Since power loss of capacitors determines their hotspot temperature, and then determines their reliability, their power loss on the average 


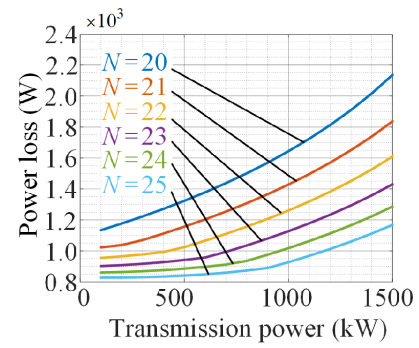

(a) primary side IGBT module

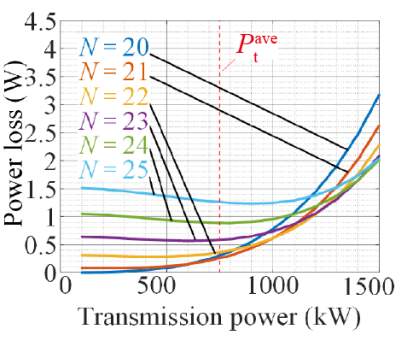

(c) input capacitor

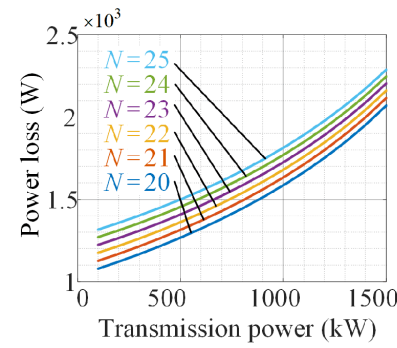

(b) secondary side IGBT module

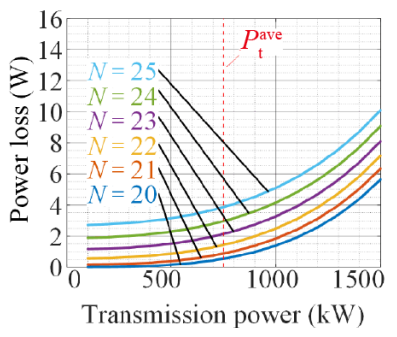

(d) output capacitor
Fig. 13. Power loss of IGBT modules and capacitors in full power range.

transmission power $\left(P_{\mathrm{t}}^{\text {ave }}\right)$ can describe the trend of their lifetime, shown as the vertical dotted line in Fig. 13(c) and (d). Therefore, the lifetime of the input capacitor first increases and then decreases, while the power loss of the output capacitor monotonously decreases, as $N$ increasing.

As shown in Fig. 13 (a) and (b), with different $P_{\mathrm{t} \text { sys }}$, power loss of primary IGBT module always decreases as $N$ increasing, and power loss of secondary IGBT module always increases. It means that the explanation of IGBT power loss applies in full power range. However, for IGBT modules, the fluctuation amplitude of $T_{\mathrm{j}}$ has more significant effects on their reliability than $T_{\mathrm{j}}$. The curve with the steeper slope in Fig. 13(a) and (b) corresponds to the redundancy design with larger $T_{\mathrm{j}}$ fluctuation amplitude, which indicates shorter lifetime for the specific mission profile. Thus, primary IGBT module lifetime increases, while secondary IGBT module lifetime decreases.

\section{Cell Redundancy Design Method}

Based on the former result analysis, a simplified system reliability evaluation method is proposed in this section. This method is applied in the next proposed cell redundancy design method considering both reliability and efficiency. The mission profile is taken into account when calculating the reliability and average efficiency of DC-SST. The best cell number is obtained by solving a multi-objective optimization.

\section{A. Simplified System Reliability Evaluation Method}

In order to describe the relationship between reliability and lifetime, the equivalent cumulative damage rate (ED) is introduced, which is defined as the reciprocal of MTTF and represents the average failure rate considering aging. As shown in Fig. 14, the equivalent cumulative damage rate of output capacitor is about six times that of IGBT modules, while the equivalent cumulative damage rate of input capacitor is

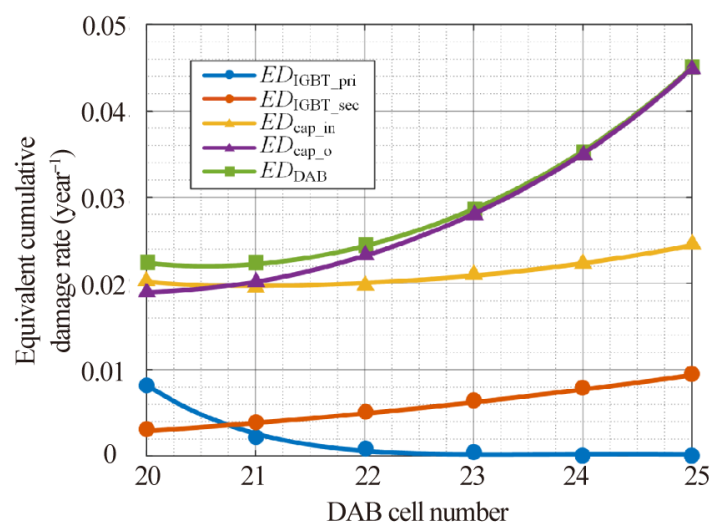

Fig. 14. ED of different devices in the DAB cell.

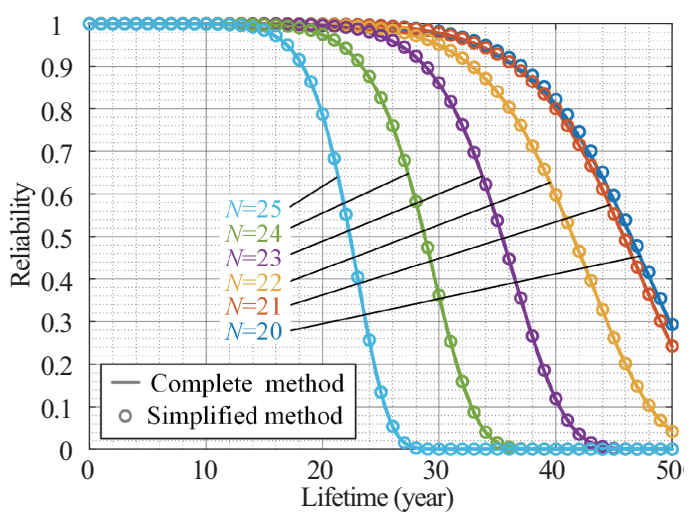

Fig. 15. Comparison between reliability curves of each DAB cell obtained by complete method and simplified method.

also about three times that of IGBT modules. It means that capacitors dominate DAB cell reliability, consistent with the existing research [27]. A possible explanation is that compared with AC converters, although capacitor lifetime has no obvious variation in DC converters, PSDs in DC converters lack linefrequency junction temperature fluctuations, which prolongs PSD lifetime in the DC converter. Therefore, the reliability of a DAB cell can be simplified as (25), only consider the reliability of input and output capacitors.

$$
R_{\mathrm{DAB}}^{\text {simp }}(N, t)=R_{\mathrm{C}}^{\mathrm{pri}}(N, t) \cdot R_{\mathrm{C}}^{\mathrm{sec}}(N, t)
$$

The reliability curves of each DAB cell with different numbers of DAB cells can also be obtained, shown as dots in Fig. 15. It is obvious that dots calculated as (25) fit lines obtained by (23). The DAB reliability error is defined as (26), which represents the similarity between reliability curves obtained by complete and simplified methods. According to Table III, when there is no redundant $\mathrm{DAB}$ cell, the relative error of reliability curves and lifetimes between complete and simplified methods is the maximum, due to the equivalent cumulative damage rate of capacitors is not larger enough than IGBT modules.

$$
e_{(N)}=\sqrt{\int_{0}^{+\infty}\left[R_{\mathrm{DAB}}^{\text {simp }}(N, t)-R_{\mathrm{DAB}}(N, t)\right]^{2} \mathrm{~d} t}
$$


TABLE III

The Relative Error Between Complete and Simplified Methods

\begin{tabular}{lcccc}
\hline \hline \multirow{2}{*}{$N$} & \multirow{2}{*}{$\begin{array}{c}\text { DAB Reliability } \\
\text { Error (\%) }\end{array}$} & \multicolumn{3}{c}{ DAB MTTF } \\
\cline { 3 - 5 } & & Comp. (year) & Simp. (year) & Error (\%) \\
\hline 20 & 0.48 & 44.76 & 45.02 & 0.58 \\
21 & 0.09 & 44.47 & 44.51 & 0.11 \\
22 & 0.10 & 40.80 & 40.85 & 0.13 \\
23 & 0.10 & 34.90 & 34.95 & 0.15 \\
24 & 0.10 & 28.34 & 28.38 & 0.15 \\
25 & 0.07 & 22.04 & 22.07 & 0.13 \\
\hline \hline
\end{tabular}

\section{B. Cell Redundancy Design Based on Multi-Objective Optimization}

Although redundancy improves the reliability of DC-SST, it also leads to efficiency issues. Thus, redundancy design is a multi-objective optimization considering both efficiency and reliability. This optimization problem can be described as (27) and (28), where $P L_{\mathrm{DC}-\mathrm{SST}}(N)$ and $E D_{\mathrm{DC}-\mathrm{SST}}(N)$ represent the total power loss and equivalent cumulative damage rate of DC-SST when there are totally $N \mathrm{DAB}$ cells respectively.

$$
\begin{gathered}
\min F(N)=\left[P L_{\mathrm{DC}-\mathrm{SST}}(N), E D_{\mathrm{DC}-\mathrm{SST}}(N)\right]^{\mathrm{T}} \\
\text { s.t. } \quad 20 \leqslant N \leqslant 25, N \in Z
\end{gathered}
$$

According to the former analysis based on Fig. 13 and Fig. 14, IGBT module power loss dominates the total power loss of DC-SST, while capacitor reliability dominates the total reliability of DC-SST. Therefore, a cell redundancy design method based on the mission profile is proposed, and (27) can be simplified as (29), where $P L_{\mathrm{IGBT}}(N)$ and $E D_{\text {cap }}(N)$ represent the power loss calculated based on IGBT modules and equivalent cumulative damage rate calculated based on capacitors when there are totally $N \mathrm{DAB}$ cells respectively.

$$
\min F(N)=\left[P L_{\mathrm{IGBT}}(N), E D_{\text {cap }}(N)\right]^{\mathrm{T}}
$$

The main idea of the proposed cell redundancy design method is that both $P L_{\mathrm{IGBT}}(N)$ and $E D_{\text {cap }}(N)$ are described according to the specific mission profile. IGBT module power loss corresponding to different $P_{\mathrm{t} \text { sys }}$ can be calculated, and the power loss profile corresponding to the given mission profile can be obtained. Thus, the average of power loss profile with $N$ cells is calculated to represent $P L_{\mathrm{IGBT}}(N)$. Similarly, equivalent cumulative damage rates of DC-SST calculated based on capacitors reliability also contain the information of the mission profile, representing $E D_{\text {cap }}(N)$.

As shown in Fig. 16, $E D_{\text {cap }}$ meets the minimum with one redundant $\mathrm{DAB}$ cell, while $P L_{\mathrm{IGBT}}$ meets the minimum with four. One solution of the multi-objective optimization is to construct a new optimization function with proper weight allocation of multiple objects [28]. The optimization can be obtained as (30), where $P L_{\mathrm{IGBT}}^{*}(N)$ is the normalization of $P L_{\mathrm{IGBT}}(N)$ based on the minimum $P L_{\mathrm{IGBT}}, E D_{\text {cap }}^{*}(N)$ is the normalization of $E D_{\text {cap }}(N)$ based on the minimum $E D_{\text {cap }}, \omega_{P L}$

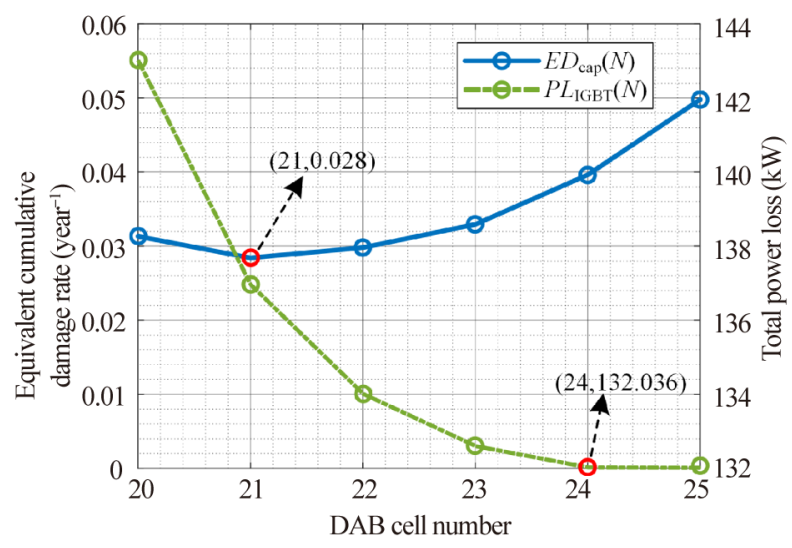

Fig. 16. Optimization of reliability and efficiency based on mission profile.

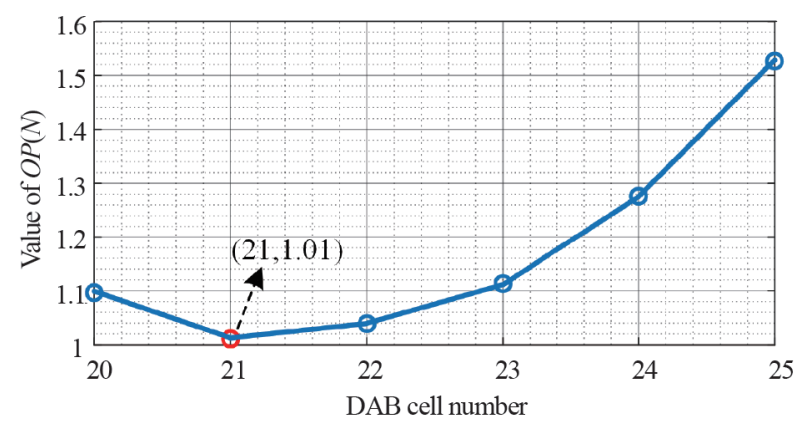

Fig. 17. Multi-optimization result of (28).

is the weight of $P L_{\mathrm{IGBT}}^{*}(N)$, and $\omega_{E D}$ is the weight of $E D_{\text {cap }}^{*}(N)$. $\omega_{P L}$ and $\omega_{E D}$ depend on the design requirement, and are selected as 0.3 and 0.7 respectively in this paper, due to more expectation of longer lifetime.

$$
\min O P(N)=\omega_{P L} \cdot P L_{\mathrm{IGBT}}^{*}(N)+\omega_{E D} \cdot E D_{\text {cap }}^{*}(N)
$$

According to the result shown in Fig. 17 and Table IV, the best design is adding one redundant cell with a maximum lifetime of 38.6 years and a proper annual average efficiency of $56.4 \%$. In this case, the redundant rate is $5 \%$, which consists of the ratio commonly used in practice [29]. It is noticed that the result is impacted by the selection of $\omega_{P L}$ and $\omega_{E D}$.

Besides the total power loss, the system reliability is also considered in the proposed cell redundancy design method. Since the system reliability is determined by capacitor reliability, which is significantly impacted by capacitor power loss, the proposed method regards the importance of the power loss of capacitors the same as PSDs. It is a meaningful discovery for the design of DC converters. Besides, the proposed method has the advantages of simple computation, due to the utilization of simplified models.

Based on the former analysis, there is another inference that for DC converters represented by the mentioned DCSST, optimization of efficiency and reliability is independent. The efficiency is determined by PSD power loss, whereas the reliability is determined by capacitor reliability, which is almost 
TABLE IV

Optimization Results of the Proposed Method

\begin{tabular}{lccccc}
\hline \hline$N$ & $P L^{*}{ }_{\text {IGBT }}$ & Efficiency (\%) & $E D_{\text {cap }}^{*}$ & Lifetime (year) & $O P$ \\
\hline 20 & 1.08 & 54.47 & 1.10 & 36.96 & 1.10 \\
21 & 1.04 & 56.40 & 1.00 & 38.27 & 1.01 \\
22 & 1.02 & 57.34 & 1.05 & 35.17 & 1.04 \\
23 & 1.01 & 57.78 & 1.16 & 30.84 & 1.11 \\
24 & 1.00 & 57.97 & 1.40 & 25.38 & 1.28 \\
25 & 1.00 & 57.97 & 1.75 & 20.05 & 1.53 \\
\hline \hline
\end{tabular}

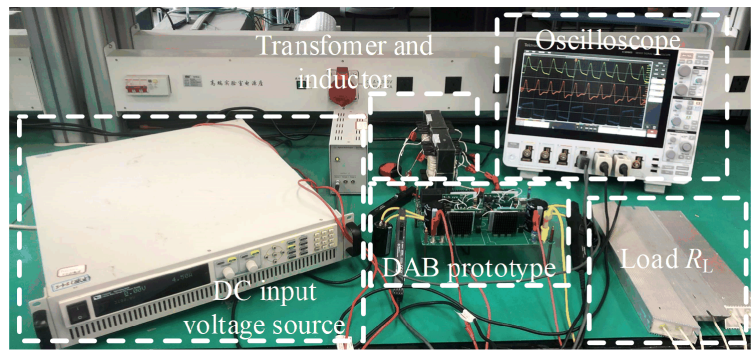

Fig. 18. Prototype for principle verification.

TABLE V

SPECIFICATION OF DAB PRototype

\begin{tabular}{lcc}
\hline \hline Parameters & Symbol & Value \\
\hline Input voltage & $V_{\text {in }}$ & $100-400 \mathrm{~V}$ \\
Output voltag & $V_{\mathrm{o}}$ & $50-240 \mathrm{~V}$ \\
Switching frequency & $f_{\mathrm{s}}$ & $50 \mathrm{kHz}$ \\
Transformer ratio of transformers & $k$ & $12: 7$ \\
Inductor & $L$ & $180 \mu \mathrm{H}$ \\
Input capacitor & $C_{\mathrm{i}}$ & $500 \mu \mathrm{F}$ \\
Output capacitor & $C_{\mathrm{o}}$ & $500 \mu \mathrm{F}$ \\
\hline \hline
\end{tabular}

impacted by capacitor power loss.

\section{EXPERIMENTAL VERIFICATION}

According to the analysis in Section $\mathrm{V}$, due to the structure of ISOP DC-SST with DAB topology, redundancy does not always increase its reliability. In this section, a $\mathrm{DAB}$ prototype based on GS66508B is constructed as shown in Fig. 18, whose parameters are shown in Table V. Several specific operating conditions are obtained to verify the effect on inductor current of the ratio between input and output voltage in each DAB cell, and the effect on $\mathrm{DAB}$ characteristic currents of redundancy.

\section{A. Voltage Ratio Effect on Inductor Current}

To verify the effect on $i_{L}$ of the ratio between $V_{\text {in }}$ and $V_{0}$, the prototype operates with $P_{\mathrm{t} \mathrm{DAB}}=612.5 \mathrm{~W}\left(V_{\mathrm{o}}=175 \mathrm{~V}, R_{\mathrm{L}}\right.$ $=50 \Omega$ ), and $i_{L}$ with different $V_{\text {in }}$ is illustrated as Fig. 19. It is shown that when $V_{\text {in }}$ is $300 \mathrm{~V}\left(=k V_{\mathrm{o}}\right), i_{L}$ is almost trapezoidal wave. When $V_{\text {in }}$ varies from $300 \mathrm{~V}$ to $180 \mathrm{~V}, I_{\text {off }}^{\text {GBB pri }}$ gradually decreases, whereas $I_{\text {off }}^{\mathrm{GBT}}$ _sec gradually increases. Besides, $i_{L}$ rms value also increases, as shown in Table VI. The experimental results validate inductor current distortion caused by $V_{\text {in }}$ reduction, which fit the analysis according to Fig. 10 well.

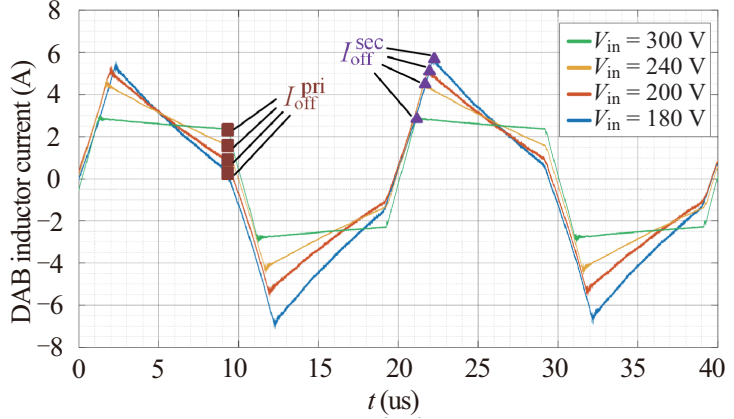

Fig. 19. Experimental result of $i_{L}$ waveforms with different $V_{\text {in }}$.

TABLE VI

RMS VALUES OF INDUCTOR CURRENT

\begin{tabular}{cccc}
\hline \hline \multirow{2}{*}{$V_{\text {in }}(\mathrm{V})$} & \multicolumn{3}{c}{$i_{L}$ rms value } \\
\cline { 2 - 4 } & Theory (A) & Experiment $(\mathrm{A})$ & Error $(\%)$ \\
\hline 300 & 2.27 & 2.19 & 3.52 \\
240 & 2.80 & 2.86 & 2.14 \\
200 & 3.42 & 3.22 & 5.96 \\
180 & 3.84 & 3.74 & 2.61 \\
\hline \hline
\end{tabular}

TABLE VII

EXPERIMENTAL Results of Characteristic CuRRents

\begin{tabular}{ccccccccc}
\hline \hline$N$ & $\begin{array}{c}V_{\text {in }} \\
(\mathrm{V})\end{array}$ & $\begin{array}{c}R_{\mathrm{L}} \\
(\Omega)\end{array}$ & $\begin{array}{c}I_{\text {cond }}^{\mathrm{psp} \text { pri }} \\
(\mathrm{A})\end{array}$ & $\begin{array}{c}I_{\text {cond }}^{\mathrm{psD} \text { sce }} \\
(\mathrm{A})\end{array}$ & $\begin{array}{c}I_{\text {off }}^{\mathrm{psp} \text { pri }} \\
(\mathrm{A})\end{array}$ & $\begin{array}{c}I_{\text {off }}^{\mathrm{psp} \text { sce }} \\
(\mathrm{A})\end{array}$ & $\begin{array}{c}I_{\text {cond }}^{\mathrm{cap} \text { in }} \\
(\mathrm{A})\end{array}$ & $\begin{array}{c}I_{\text {cond }}^{\mathrm{cap} \text { o }} \\
(\mathrm{A})\end{array}$ \\
\hline 20 & 171.4 & 50 & 1.294 & 2.218 & 1.353 & 2.228 & 0.556 & 0.914 \\
21 & 163.2 & 52.5 & 1.269 & 2.175 & 1.014 & 2.623 & 0.515 & 0.941 \\
22 & 155.8 & 55 & 1.255 & 2.151 & 0.826 & 2.880 & 0.514 & 0.966 \\
23 & 149.1 & 57.5 & 1.260 & 2.160 & 0.732 & 3.103 & 0.526 & 1.172 \\
24 & 142.8 & 60 & 1.266 & 2.170 & 0.637 & 3.308 & 0.543 & 1.309 \\
25 & 137.1 & 62.5 & 1.282 & 2.198 & 0.518 & 3.481 & 0.580 & 1.515 \\
\hline \hline
\end{tabular}

\section{B. Redundancy Effect on Characteristic Currents}

Besides $V_{\text {in }}$ decrease, redundancy also reduces $P_{\mathrm{t} \text { DAB }}$, with the same $P_{\mathrm{t} \text { sys }}$. Therefore, the prototype operates with $\bar{V}_{\mathrm{o}}=100 \mathrm{~V}$, and $R_{L}$ is varied continually to imitate the variation of $P_{\mathrm{t} \mathrm{DAB}}$ in the DC-SST with $P_{\mathrm{t} \text { sys }}=4 \mathrm{~kW}$ when $N$ changes. When there is no redundancy, $V_{\text {in }}=171.43 \mathrm{~V}\left(=k V_{\mathrm{o}}\right)$. If the initial cell number $N_{0}=20$, the total input voltage of DC-SST is $3428.6 \mathrm{~V}$. Thus, the experimental result of $\mathrm{DAB}$ characteristic currents analyzed in Fig. 11 is illustrated in Table VII and Fig. 20. The result shows that as $N$ increasing, both $I_{\text {cond }}^{\mathrm{PSD} \text { pri }}$ and $I_{\text {cond sec }}^{\mathrm{PSD}}$ are almost constant, both $I_{\text {off }}^{\mathrm{PSD} \_ \text {sec }}$ and $I_{\text {cond }}^{\text {cap io }}$ increases, $I_{\text {off }}^{\mathrm{PSD} \text { pri }}$ decreases, while $I_{\text {cond }}^{\text {ap in }}$ first slightly decreases and then slightly increases. All of these characteristic currents have similar trends to analysis results in Fig. 11. Therefore, power loss and thermal stress of them can be obtained, which are similar as analysis in trend. Efficiency and reliability are accordingly influenced by redundancy, and the optimization is able to find the optimal redundancy design.

According to the analysis in Section IV, this phenomenon exists as long as there is imbalance between input and output voltage in each cell. Thus, the proposed optimization is suitable for any ISOP isolation DC-SST with different control methods. 


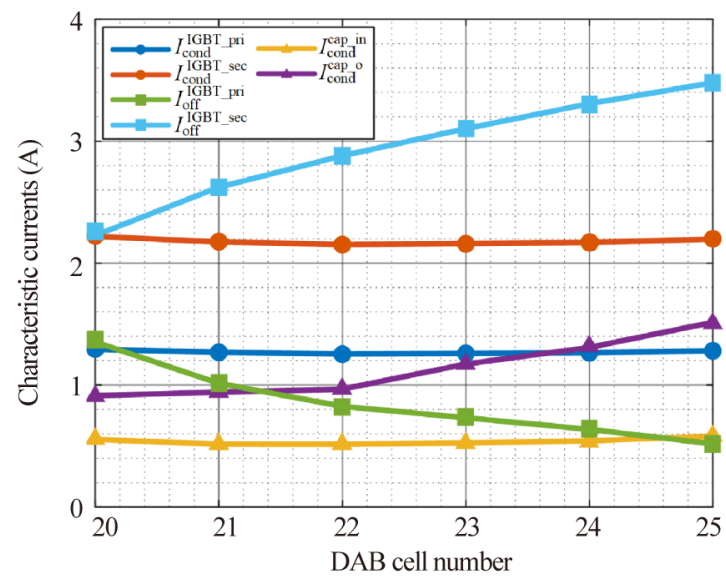

Fig. 20. Experimental DAB characteristic currents.

\section{CONCLUSION}

In this paper, a redundancy design method of the modular DC-SST utilized in power distribution applications is proposed considering both reliability and efficiency. Firstly, the reliability is evaluated, considering the long-term mission profile and aging of critical devices. Besides, the power loss models of the PSD and the capacitor taking into account the cell number are given. The power loss of DC-SST considering the long-term mission profile is computed. According to evaluation results, the efficiency of the DC-SST is dominated by IGBTs, whereas the reliability of it is dominated by capacitors. Therefore, a simplified reliability model of DC-SST is proposed, and a power loss approximate calculation is utilized for simpler optimization description and solution. With the evaluation of both reliability and efficiency considering different cell numbers, a multi-objective optimization is solved to realize the optimal redundancy design. The result shows that one redundant cell is optimal, with a maximum lifetime of 38.6 years and a proper annual average efficiency of $56.4 \%$. In this case, the redundant rate is $5 \%$, which consists of the redundant rate commonly used in practice. Experimental results based on a prototype verify the analysis in the proposed method.

The proposed method is credible since the long-term mission profile is taken into account, and suitable for all of the ISOP isolation DC-SSTs with different control methods. Besides, it also rediscovers the importance of capacitor power loss, and provides a guideline for device selection. IGBTs with low power loss are selected to increase efficiency, and capacitors with low power loss are selected to meet lifetime requirements.

\section{REFERENCES}

[1] Z. Li, F. Gao, C. Zhao, Z. Wang, H. Zhang, P. Wang, and Y. Li, "Research review of power electronic transformer technologies" in Proceedings of the CSEE, vol. 38, no. 2, pp. 1274-1289, Mar. 2018.

[2] K. Ma, M. Liserre, F. Blaabjerg, and T. Kerekes, "Thermal loading and lifetime estimation for power device considering mission profiles in wind power converter," in IEEE Transactions on Power Electronics, vol. 30, no. 2, pp. 590-602, Feb. 2015.

[3] H. Liu, K. Ma, Z. Qin, P. C. Loh, and F. Blaabjerg, "Lifetime estimation of MMC for offshore wind power HVDC application," in IEEE Journal of Emerging and Selected Topics in Power Electronics, vol. 4, no. 2, pp. 504-511, Jun. 2016.
[4] H. Huang and P. A. Mawby, "A lifetime estimation technique for voltage source inverters," in IEEE Transactions on Power Electronics, vol. 28 no. 8, pp. 4113-4119, Aug. 2013.

[5] Q. Ma, "Optimized design and reliability evaluation of DC solid state transformer based on SiC MOSFET," M. S. thesis, School of Electrical Engineering, Chongqing University, Chongqing, China, 2017.

[6] J. E. Huber and J. W. Kolar, "Optimum number of cascaded cells for high-power medium-voltage AC-DC converters," in IEEE Journal of Emerging and Selected Topics in Power Electronics, vol. 5, no. 1, pp. 213-232, Mar. 2017.

[7] P. Tu, S. Yang, and P. Wang, "Reliability- and cost-based redundancy design for modular multilevel converter," in IEEE Transactions on Industrial Electronics, vol. 66, no. 3, pp. 2333-2342, Mar. 2019.

[8] H. Jing, J. Xu, Y. Xu, C. Zhao, W. Jiang, and H. Zhang, "Reliability analysis of MMC considering the submodule correlations," in Proceedings of the CSEE, vol. 37, no. 13, pp. 175-182, Jul. 2017.

[9] V. Samavatian, H. Iman-Eini, and Y. Avenas, "Reliability assessment of multistate degraded systems: An application to power electronic systems," in IEEE Transactions on Power Electronics, vol. 35, no. 4, pp. 4024 4032, Apr. 2020

[10] M. Chen, Y. Chen, B. Gao, W. Lai, and S. Xu. "Lifetime estimation of IGBT module considering influence of aging process on thermal parameters," in Proceedings of the CSEE, vol. 37, no. 18, pp. 223-232, 338, Sept. 2017.

[11] R. Yao, H. Li, W. Lai, A. S. Bahman, and F. Iannuzzo, "Lifetime analysis of metallized polypropylene capacitors in modular multilevel converter based on finite element method," in IEEE Journal of Emerging and Selected Topics in Power Electronics, Early Access.

[12] Y. Wang, K. Wang, C. Li, Z. Zheng, and Y. Li, "System-level efficiency evaluation of isolated DC/DC converters in power electronics transformers for medium-voltage DC systems," in IEEE Access, vol. 7, pp. 48445-48458, 2019.

[13] B. Zhao, Q. Song, and W. Liu, "Efficiency characterization and optimization of isolated bidirectional DC-DC converter based on dualphase-shift control for DC distribution application," in IEEE Transactions on Power Electronics, vol. 28, no. 4, pp. 1711-1727, Apr. 2013.

[14] W. Lei, J. Liu, G. Lv, C. Lv, and R. Cao, "Review of reliability comprehensive analysis and evaluation methods for key components and system of large capacity power electronic equipment," in High Voltage Engineering, vol. 46, no. 10, pp. 3353-3361, Oct. 2020.

[15] R. Cao, Y. Li, Y. Zhang, X. Liu, C. Lv, and J. Zhang, "Thermal modeling of power semiconductor devices with heat sink considering ambient temperature dynamics," in Proceedings of 2020 IEEE 9th International Power Electronics and Motion Control Conference (IPEMC2020-ECCE Asia), Nanjing, China, 2020, pp. 290-295.

[16] Y. Zhang, H. Wang, Z. Wang, Y. Yang, and F. Blaabjerg, "The impact of mission profile models on the predicted lifetime of IGBT modules in the modular multilevel converter," in Proceedings of IECON 2017 - 43rd Annual Conference of the IEEE Industrial Electronics Society, Beijing, China, 2017, pp. 7980-7985.

[17] K. C. Norris and A. H. Landzberg, "Reliability of controlled collapse interconnections," in IBM Journal of Research and Development, vol. 13, no. 3, pp. 266-271, May 1969.

[18] J. Berner, "Load-cycling capability of HiPak IGBT modules," in ABB Application Note 5SYA 2043-02, 2012.

[19] M. A. Miner, "Cumulative damage in fatigue Jour," in Journal of Applied Mechanics, vol. 12, no. 3, Jan. 1945.

[20] C. Lv, J. Liu, Y. Zhang, W. Lei, R. Cao, and G. Lv, "Reliability modeling for metallized film capacitors based on time-varying stress mission profile and aging of ESR," in IEEE Journal of Emerging and Selected Topics in Power Electronics, Early Access.

[21] R. Yao, M. Zheng, H. Li, W. Lai, X. Wang, and H. Long, "Reliability modeling and analysis on metallized film capacitors for MMC," in Proceedings of 2019 10th International Conference on Power Electronics and ECCE Asia (ICPE 2019 - ECCE Asia), Busan, Korea (South), 2019, pp. 1854-1860.

[22] D. Zhou, H. Wang, and F. Blaabjerg, "Mission profile based system-level reliability analysis of DC/DC converters for a backup power application," in IEEE Transactions on Power Electronics, vol. 33, no. 9, pp. 80308039, Sept. 2018.

[23] ReliaSoft Corporation, "Life data analysis reference," 2015. [Online]. Available: http://reliawiki.org/index.php/Life_Data_Analysis_Reference_ Book

[24] R. Cao, Y. Zhang, Y. Li, X. Liu, C. Lv, and D. Liu, "Redundant design of modular DC solid-state transformer based on the long term reliability evaluation," in Proceedings of 2020 4th International Conference on 
HVDC (HVDC), Xi'an, China, 2020, pp. 730-735.

[25] F. Richardeau and T. T. L. Pham, "Reliability calculation of multilevel converters: Theory and applications," in IEEE Transactions on Industrial Electronics, vol. 60, no. 10, pp. 4225-4233, Oct. 2013.

[26] X. Yu and A. M. Khambadkone, "Reliability analysis and cost optimization of parallel-inverter system," in IEEE Transactions on Industrial Electronics, vol. 59, no. 10, pp. 3881-3889, Oct. 2012.

[27] S. Peyghami, P. Davari, and F. Blaabjerg, "System-level reliabilityoriented power sharing strategy for DC power systems," in IEEE Transactions on Industry Applications, vol. 55, no. 5, pp. 4865-4875, Sept.-Oct. 2019.

[28] G. Adinolfi, G. Graditi, P. Siano, and A. Piccolo, "Multiobjective optimal design of photovoltaic synchronous Boost converters assessing efficiency, reliability, and cost savings," in IEEE Transactions on Industrial Informatics, vol. 11, no. 5, pp. 1038-1048, Oct. 2015.

[29] P. Yu, W. Fu, L. Wang, Z. Zhou, G. Wang, and Z. Zhang, "Reliabilitycentered maintenance for modular multilevel converter in HVDC transmission application," in IEEE Journal of Emerging and Selected Topics in Power Electronics, Early Access.

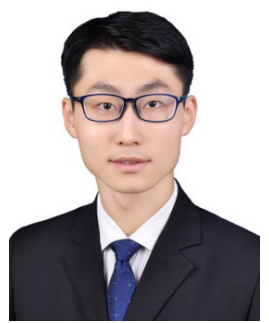

Yang $\mathrm{Li}$ received the B.S. degree in electrical engineering from Xi'an Jiaotong University (XJTU), Xi'an, China, in 2019. He is currently working toward the $\mathrm{Ph} . \mathrm{D}$. degree in electrical engineering at $\mathrm{Xi}$ 'an Jiaotong University, Xi'an, China.

His research interests include reliability evaluation and optimization design of power electronic systems.

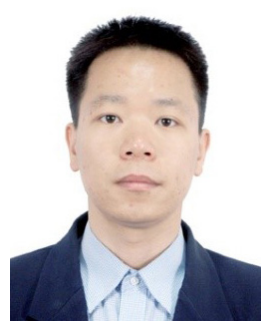

Yan Zhang received the $\mathrm{Ph} . \mathrm{D}$. degree in electrical engineering from Xi'an Jiaotong University (XJTU), Xi'an, China, in 2014. He is currently an Associate Professor with the School of Electrical Engineering, XJTU. From early 2016 to 2017 , he was a Postdoctoral Research Fellow with the Department of Electrical and Computer Engineering, Queen's University, Kingston, ON, Canada. He has presided over research projects of the National Natural Science Foundation, the China Postdoctoral Science and Province Foundation, and the State Key Lab Foundation. He has authored or coauthored more than 70 technical papers in peer reviewed journals and conference proceedings and holds 10 China issued invention patents.

His research interests include topology, model and control of power electronic systems, high-efficiency resonant power converters, and power electronics equipment reliability.

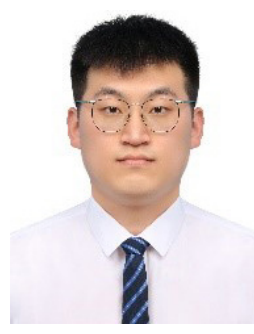

Rui Cao received the B.S. degree in electrical engineering from Hefei University of Technology, Hefei, China, in 2018. He is currently pursuing the M.S. degree in electrical engineering at $\mathrm{Xi}$ 'an Jiaotong University, Xi'an, China.

His research interests include thermal modeling of power semiconductor devices, reliability evaluation of power electronic systems and optimization design of power electronic systems.

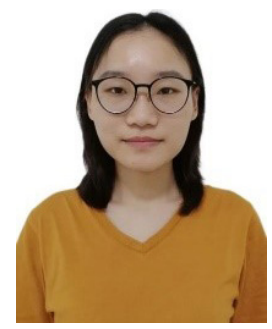

Xue Liu received the B.S. degree in electrical engineering from Changsha University of Science and Technology, Changsha, China, in 2019. She is currently pursuing the M.S. degree in electrical engineering with Xi'an Jiaotong University, Xi'an, China.

Her research interest includes reliability evaluation and optimization design of power electronic systems.

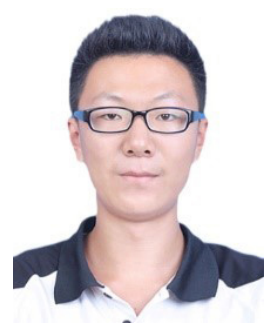

Chunlin Lv received the B.S. degree in electrical engineering from Chongqing University, Chongqing, China, in 2018. He is currently working toward the $\mathrm{Ph} . \mathrm{D}$. degree in electrical engineering at Xi'an Jiaotong University, Xi'an, China.

His research interests include reliability modeling of capacitors, reliability evaluation of power electronic systems and optimization design of power electronic systems.

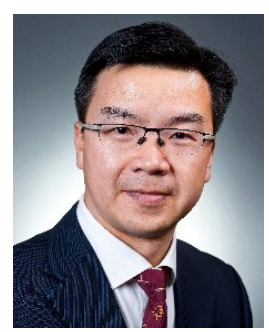

Jinjun Liu received the B.S. and Ph.D. degrees in electrical engineering from Xi'an Jiaotong University (XJTU), Xi'an, China, in 1992 and 1997, respectively.

He then joined the XJTU Electrical Engineering School as a faculty. From late 1999 to early 2002, he was with the Center for Power Electronics Systems, Virginia Polytechnic Institute and State University, Blacksburg, VA, USA, as a Visiting Scholar. In late 2002, he was promoted to a Full Professor and then the Head of the Power Electronics and Renewable Energy Center at XJTU, which now comprises more than 20 faculty members and over 200 graduate students and carries one of the leading power electronics programs in China. From 2005 to early 2010, he served as an Associate Dean of Electrical Engineering School at XJTU, and from 2009 to early 2015, the Dean for Undergraduate Education of XJTU. He is currently a XJTU Distinguished Professor of Power Electronics. He coauthored 3 books (including one textbook), published over 500 technical papers in peerreviewed journals and conference proceedings, holds over 50 invention patents (China/US/Europe), and delivered for many times plenary keynote speeches and tutorials at IEEE conferences or China national conferences in power electronics area. His research interests include modeling, control, and design methods for power converters and electronified power systems, power quality control and utility applications of power electronics, and micro-grids for sustainable energy and distributed generation.

Dr. Liu received for eight times governmental awards at national level or provincial/ministerial level for scientific research/teaching achievements. He also received the 2006 Delta Scholar Award, the 2014 Chang Jiang Scholar Award, the 2014 Outstanding Sci-Tech Worker of the Nation Award, the 2016 State Council Special Subsidy Award, the IEEE Transactions on Power Electronics 2016 Prize Paper Award, and the Nomination Award for the Grand Prize of 2020 Bao Steel Outstanding Teacher Award. He served as the IEEE Power Electronics Society Region 10 Liaison and then China Liaison for 10 years, an Associate Editor for the IEEE Transactions on Power Electronics for 13 years, 2015-2019 Executive Vice President and 2020-2021 Vice President for membership of IEEE PELS, and was elevated IEEE Fellow in 2018. He was on the Board of China Electrotechnical Society 2012-2020 and was elected the Vice President in 2013 and the Secretary General in 2018 of the CES Power Electronics Society. Since 2013, he has been the Vice President for International Affairs, China Power Supply Society (CPSS) and since 2016, the inaugural Editor-in-Chief of CPSS Transactions on Power Electronics and Applications. Since 2013, he has been serving as the Vice Chair of the Chinese National Steering Committee for College Electric Power Engineering Programs. 